\title{
Heavy rains and extreme rainfall-runoff events in Central Europe from 1951 to 2002
}

\author{
M. Müller ${ }^{1,2}$, M. Kašpar ${ }^{1}$, and J. Matschullat ${ }^{3}$ \\ ${ }^{1}$ Institute of Atmospheric Physics AS CR, Prague, The Czech Republic \\ ${ }^{2}$ Charles University, Faculty of Science, Prague, The Czech Republic \\ ${ }^{3}$ TU Bergakademie, Freiberg, Germany
}

Received: 27 November 2008 - Revised: 12 February 2009 - Accepted: 24 February 2009 - Published: 19 March 2009

\begin{abstract}
Runoff data were used to better select historically significant precipitation events. The suggested criterion $Q_{x}$ expresses the increase of a stream runoff over up to four days in a row. Tests confirmed that $Q_{x}$ maxima correspond to maxima of areal precipitation in the respective catchment. Ten significant precipitation events in summer half-years from 1951 to 2002 were selected in 25 catchments each, and further studied in respect to spatial extent, simultaneous occurrence in various river basins, seasonal distribution, and temporal variability. Four regions were recognised within Central Europe that show related seasonality and simultaneous occurrence of events. The main coincidence of significant precipitation events was confirmed between the Austrian Alps and Bohemia and Saxony on one hand, and Moravia, Silesia, and Western Slovakia on the other hand. Significant events typically emerge here during peak summer, in the south-eastern area of the Alps during autumn months, in the South-Eastern Carpathians from May to July, and in Western Germany in spring or autumn. Episodes with less significant precipitation events (around 1960 and 1990) alternate with inverse episodes (1970's, second half of the 1990's). A reasonable selection of reference events opens the door to a quantitative evaluation of dynamic and thermodynamic conditions typical for heavy rains in various parts of Central Europe.
\end{abstract}

\section{Introduction}

Significant and serious floods of major Central-European rivers (with catchments of at least several thousand $\mathrm{km}^{2}$ ) are connected with heavy precipitation events. These events

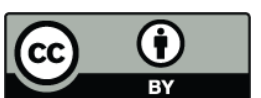

Correspondence to: M. Müller

(muller@ufa.cas.cz coincide with specific conditions in the related river basin, primarily snow melt in winter and spring, and possibly increased preceding soil saturation in summer. The events are characterized by (i) above average high precipitation sums and intensities for both time of year and for the given region, by (ii) a duration of several days, and (iii) by a relatively large area impacted by the precipitation. Such events are usually connected to typical synoptic-scale structures, e.g., cyclones, atmospheric fronts, etc.

Relations between circulation conditions and hydrometeorological consequences are generally studied by several approaches, like real data analysis (e.g., Rezáčová et al., 2005), circulation type classifications (e.g., Ustrnul and Czekierda, 2001), and numerical simulations (e.g., Jung et al., 2004). Except for isolated case studies, all these approaches demand to compile a set of significant events that are investigated further and compared. However, there is no exact and unanimously agreed criterion to select the reference events. Therefore, some authors use sets of floods defined by economic losses (e.g., Porcú et al., 2003) or by the peak-overthreshold approach (e.g., Mudelsee et al., 2004). However, runoff is usually also affected by various parameters that are not connected to the actual atmospheric circulation. This induces a certain discrepancy between studied causes and effects. In fact, the circulation conditions should be related only to the resulting precipitation characteristics. Some authors select the significant events in respect to the highest precipitation sums, recorded at individual rain gauge stations (e.g., Jansa et al., 2001), possibly linking them with circulation indices (Martín et al., 2006). However, site-related precipitation maxima hardly represent a larger region. Areal precipitation amounts would obviously be a more appropriate selection criterion (Kašpar and Müller, 2008).

Published by Copernicus Publications on behalf of the European Geosciences Union. 
Heavy precipitation cannot hit all of Central Europe simultaneously. Thus, significant precipitation events have to be studied in individual sub-regions. To comply with hydrological applications, these sub-regions should correspond to large river basins rather than administrative units. However, to compute the areal precipitation amounts within many catchments across Central Europe, precipitation data from thousands of stations would be needed. These data are generally not accessible or even available. Significant precipitation events can be identified not only by a direct evaluation of precipitation measurements but also through the analysis of runoff responses. If used correctly, the latter approach may express the hydrological effect of the precipitation event even better - the main objective of this study. This work aims at (i) proposing a method to assess the extremity of areal precipitation within a river basin through runoff data, (ii) verifying the method by comparison with the precipitation-based approach, (iii) presenting significant precipitation events in 25 independent Central-European river basins (Fig. 1), and (iv) studying them from the perspective of seasonal and inter-annual distribution, simultaneous occurrence etc. Since snow characteristics can strongly influence related results, this study was restricted to the summer half-years (May-October), when significant snowfall in precipitation or significant snow melt processes can be neglected.

\section{Data and selection methods for significant events}

Significant precipitation events with corresponding hydrological responses were selected using runoff data, while precipitation data were used for evaluating the results within several river basins. Available data series from both rain gauge and discharge gauge stations were of variable length. The period from 1951 to 2002 was selected as a compromise between length of the period and completeness of the data sets. Within 52 summer half-years, 10 significant events were chosen from each river basin to obtain a meaningful return period of such an event of approximately at least five years.

\subsection{Selection based on runoff data}

The hydrological data needed to select significant precipitation events were provided by the Global Runoff Data Centre (GRDC) in Koblenz, Germany. That database comprises values of mean daily flow $\left(Q_{d}\right)$ for many rivers worldwide. Here, river basins were selected, based upon catchment area and length of the data series. Areas up to ca. $25000 \mathrm{~km}^{2}$ seemed to be most promising. Transformation processes of flood waves in larger catchments are usually too complex, thus preventing the use of these data as an indicator for the extremity of a precipitation event that caused a flood. All selected river basins and gauge stations are listed in Table 1 and depicted in Fig. 1.

When evaluating the extremity of precipitation events using runoff data, the rainfall impact must be distinguished from other effects that influence runoff, mainly the preceding soil saturation. Such effects can be filtered by selecting an appropriate hydrological indicator. Several ones of these are discussed here in respect to their ability to express the extremity of precipitation events:

- $Q_{\max }$...local maximum of absolute $Q_{d}$ values;

- $Q_{\max }-Q_{\min } \ldots$ difference between a $Q_{\max }$ value and the $Q_{d}$ minimum, registered from 1 to 4 days before $\left(\sim Q_{\min }\right)$;

- $Q_{\max } / Q_{\min }$...ratio of these maxima and minima of $Q_{d}$.

The criterion $Q_{\max }$ could not be used because runoff maxima do not necessarily coincide with precipitation maxima. $Q_{\max }-Q_{\min }$ seems to be more suitable but obviously underemphasizes the role of the preceding saturation. When using this indicator, events with the same difference between the $Q_{\max }$ and $Q_{\min }$ values are assessed as identically extreme independent from $Q_{\min }$ (Fig. 2). In fact, a precipitation amount $R$ usually produces comparatively higher discharge increase with $Q_{\min }(A)$ than with $Q_{\min }(B)$ if $Q_{\min }(A)>Q_{\min }(B)$ because less precipitation water is retained in the catchment.

Inversely, $Q_{\max } / Q_{\min }$ overemphasizes the role of the antecedent saturation because if, e.g., $Q_{\min }(A)=2 Q_{\min }(B)$, then $Q_{\max }(A)$ would be lower than $2 Q_{\max }(B)$. The identical extreme events should lie on parabolic lines in Fig. 2, since the role of the antecedent saturation relatively drops with higher $Q_{\min }$. Therefore, a compound criterion $Q_{x}$ was designed that combines information of both the difference and the proportion between $Q_{\max }$ and $Q_{\min }$. The criterion $Q_{x}$ is calculated according to

$Q_{x}=\frac{\left(Q_{\max }-Q_{\min }\right) Q_{\max }}{Q_{\min }+Q_{\text {med }}}$,

where $Q_{\max }$ is a local maximum of absolute values of mean daily flow, $Q_{\min }$ is the local minimum of $Q_{d}$ registered from 1 to 4 days before, and $Q_{\text {med }}$ is the median of $Q_{d}$ during summer half-years. If $Q_{\min }$ was very small, $Q_{x}$ would increase inadequately - therefore the weight of $Q_{\min }$ is reduced by $Q_{\text {med }}$ in the denominator. Nevertheless, if the catchment is fully saturated, a precipitation amount $R$ produces a constant discharge increase independent from $Q_{\min }$ because theoretically no precipitation water is being retained in the catchment. The critical point, representing full saturation, was subjectively assessed with $Q_{\min }=Q_{\text {sat }}$ where $Q_{\text {sat }}$ is the 0.99-th percentile of the $Q_{d}$ distribution during summer halfyears. In the rare cases when $Q_{\min }>Q_{\text {sat }}, Q_{\min }$ was replaced by $Q_{\text {sat }}$ and $Q_{\max }$ by $Q_{\max }-\left(Q_{\min }-Q_{\text {sat }}\right)$. This correction is necessary only in case of extra high $Q_{\min }$ values - the subjectively chosen 0.99 -th percentile seems to be a rather appropriate threshold. 


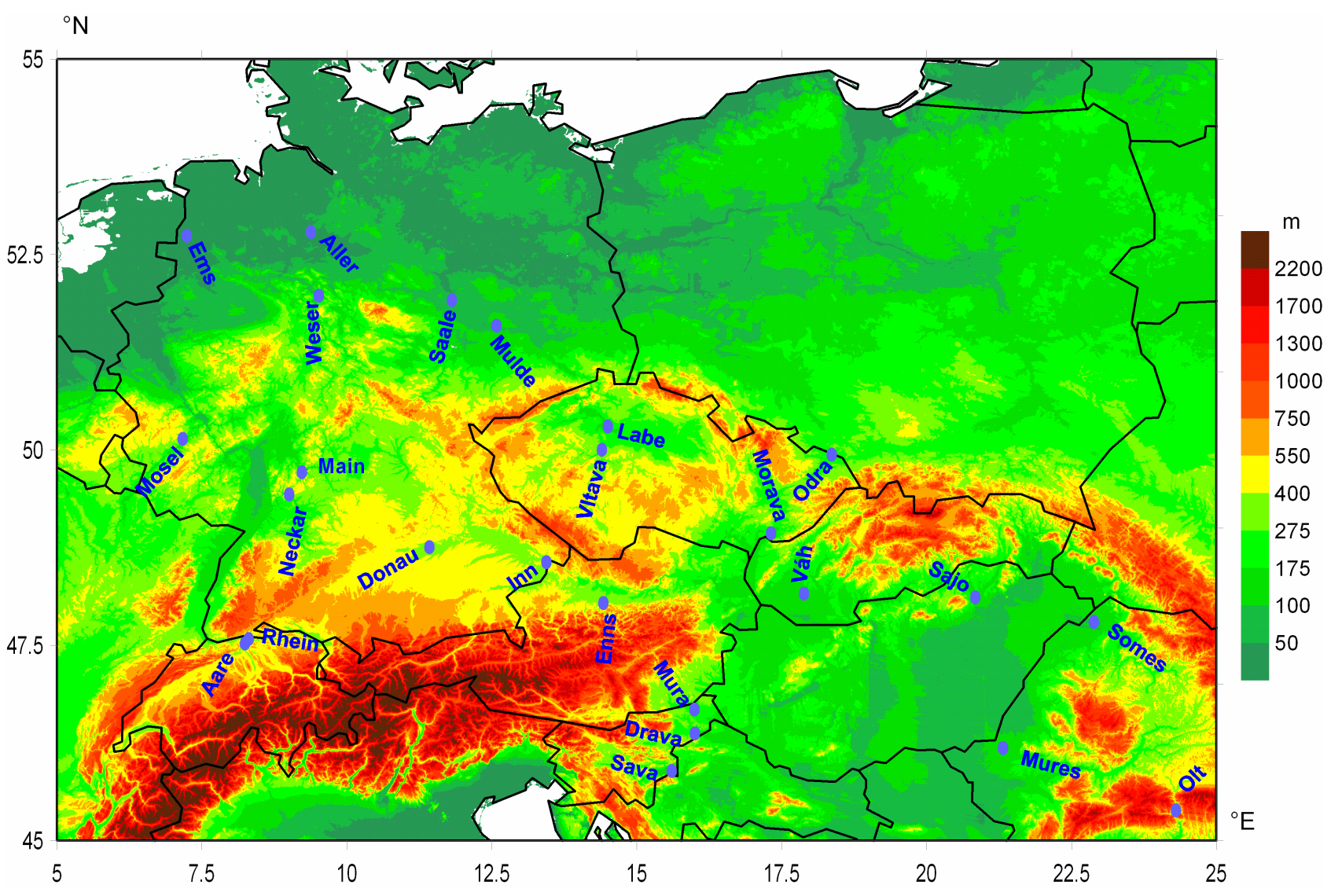

Fig. 1. Discharge gauge stations, closing particular river basins, where significant precipitation events were identified. The position of the river name and its direction relatively to the station suggest the course of the river up to the station.

\subsection{Selection based on precipitation data}

To verify the selection method presented above, the extremity of large-scale precipitation in several river basins was studied using areal precipitation amounts. First, daily precipitation totals from gauge stations were interpolated by kriging into a regular grid. Then, areal daily precipitation amounts within a river basin were expressed as the mean precipitation total, calculated from grid-points located within the river basin.

Daily precipitation totals do not represent significant precipitation events adequately because such an event usually lasts for several days. Thus, periods of three days were used to evaluate the extremity of precipitation events. Nevertheless, the temporal distribution of the precipitation in these days has to be observed since a temporal concentration of rain makes an event more dangerous from the hydrological point of view. The mean value does not express this, leading to the criterion:

$R_{x}=\frac{3 R_{\max }+2 R_{\mathrm{med}}+R_{\min }}{6}$,

where $R_{\max }$ is the maximum daily areal precipitation amount, $R_{\text {med }}$ is the medium daily areal precipitation amount, and $R_{\min }$ is the minimum daily areal precipitation amount in the three-day period. Further details are discussed in Kašpar and Müller (2008).

\subsection{Discussion and comparison of the selection methods}

It should be discussed first whether the selection of $Q_{x}$ is representative enough for a river basin when data from a single discharge gauge station are used. A comparison of high $Q_{x}$ values at three stations in the Inn River catchment is presented: Passau (located close to its mouth into the Danube: $26084 \mathrm{~km}^{2}$ ) Wasserburg (located upstream from the confluence with the Salzach: $11983 \mathrm{~km}^{2}$ ); Burghausen (located on the Salzach: $6649 \mathrm{~km}^{2}$ ). Figure 3 shows that particularly high $Q_{x}$ values at the closing station of the river basin are accompanied by high values of $Q_{x}$ at least at one of the stations upstream. The cases with values of $Q_{x}$ at one of the stations upstream (Wasserburg or Burghausen) higher than downstream (Passau) can be explained by transformation processes of flood waves.

The sets of the ten most significant events selected by $Q_{x}$ were further compared with the ten most significant events according to $R_{x}$, within five river basins, where both runoff 
Table 1. River basins and discharge gauge stations. The last column indicates the proportion between maximal $Q_{d}$ in summer and in winter half-years.

\begin{tabular}{|c|c|c|c|c|c|c|c|}
\hline \multirow{2}{*}{ River } & \multirow{2}{*}{ Station } & \multirow{2}{*}{$\begin{array}{r}\text { Area } \\
{\left[\mathrm{km}^{2}\right]}\end{array}$} & \multirow{2}{*}{ Period covered with data } & \multicolumn{3}{|c|}{ Most significant event ( $\mathrm{V}-\mathrm{X}$ ) according to $Q_{x}$} & \multirow{2}{*}{$\mathrm{S} / \mathrm{W}$} \\
\hline & & & & Date & $Q_{\max }\left[\mathrm{m}^{3} \cdot \mathrm{s}^{-1}\right]$ & $Q_{\min }\left[\mathrm{m}^{3} \cdot \mathrm{s}^{-1}\right]$ & \\
\hline Aare & Untersiggenthal & 17625 & $1951-2002$ & 24 Jun 1973 & 1787 & 593 & 0.99 \\
\hline Aller & Rethem & 14730 & $1951-2001$ & 31 Oct 1998 & 399 & 178 & 0.49 \\
\hline Donau/Danube & Ingolstadt & 20001 & $1951-2001$ & 24 May 1999 & 2191 & 709 & 1.57 \\
\hline Drau/Drava & Borl & 14662 & 1954-1980, 1990-2002 & 8 Oct 1998 & 1512 & 22 & 1.22 \\
\hline Ems & Versen & 8369 & $1951-2002$ & 2 Jul 1981 & 325 & 32 & 0.82 \\
\hline Enns & Steyer & 5915 & $1965-2001$ & 1 Aug 1977 & 1440 & 111 & 1.52 \\
\hline Inn & Passau & 26084 & $1951-2002$ & 10 Jul 1954 & 6360 & 1470 & 1.99 \\
\hline Labe/Elbe & Brandýs n. L. & 13109 & $1951-2002$ & 11 Aug 1964 & 718 & 75 & 0.69 \\
\hline Main & Kleinheubach & 21505 & 1959-2002 & 29 Oct 1998 & 867 & 244 & 0.60 \\
\hline Morava/March & Strážnice & 9147 & $1951-2002$ & 4 Jul 1954 & 550 & 17 & 1.42 \\
\hline Moselle/Mosel & Cochem & 27088 & $1951-2002$ & 14 May 1970 & 2740 & 438 & 0.85 \\
\hline Mulde & Bad Düben & 6171 & $1961-2002^{*}$ & 14 Aug 2002 & 1570 & 75 & 1.15 \\
\hline Mur/Mura & Gornja Radgona & 10197 & 1951-2001 & 24 Jun 1973 & 1102 & 171 & 1.10 \\
\hline Mures/Maros & Arad & 27280 & $1952-2002$ & 18 May 1970 & 2210 & 732 & 1.51 \\
\hline Neckar & Rockenau & 12710 & $1951-2002$ & 24 May 1978 & 1640 & 135 & 0.78 \\
\hline Odra/Oder & Bohumín & 4662 & $1951-2002$ & 8 Jul 1997 & 1830 & 22 & 5.17 \\
\hline Olt & Cornet & 13733 & $1967-2002$ & 4 Jul 1975 & 1778 & 173 & 2.63 \\
\hline Rhein/Rhine & Rekingen & 14718 & $1951-2002$ & 13 May 1999 & 1793 & 676 & 1.61 \\
\hline Saale & Calbe & 23719 & $1951-2002$ & 15 Jul 1954 & 440 & 50 & 0.91 \\
\hline Sava & Catez & 10186 & 1956-2002 & 26 Sep 1973 & 2480 & 98 & 0.93 \\
\hline Slaná/Sajo & Felsözsolca & 6440 & 1951-1995 & 29 Jul 1960 & 319 & 76 & 1.26 \\
\hline Somes/Szamos & Satu Mare & 15388 & $1951-2002$ & 15 May 1970 & 3216 & 548 & 1.82 \\
\hline Váh & Šala & 11218 & $1951-2001$ & 10 Jul 1997 & 1374 & 174 & 1.09 \\
\hline Vltava & Praha & 26720 & 1951-2002 & 14 Aug 2002 & 4970 & 1250 & 3.98 \\
\hline Weser & Bodenwerder & 15924 & $1951-2002$ & 18 Jul 1965 & 832 & 90 & 0.92 \\
\hline
\end{tabular}

* Precipitation data 1951-2002.

and precipitation data were at our disposal. If the selection result were identical for both criteria, every catchment would be represented by ten symbols, and higher $R_{x}$ values would correspond to higher $Q_{x}$ values in Fig. 4a. However, if the selection by both criteria were completely different, every catchment would be represented by up to twenty symbols. Ten of these would be located in the upper left part, the others in the bottom right part of the diagram.

The main conclusions are as follows:

- significant events selected by both $R_{x}$ and $Q_{x}$ is very similar in mountain and rather homogeneous catchments such as of the Mulde and the Odra rivers. The maxima of both criteria correspond; the sets of significant events in terms of $R_{x}$ and $Q_{x}$ are almost identical but their ranking can be somewhat different;

- the criteria $R_{x}$ and $Q_{x}$ are also related when a stream is significantly influenced by reservoirs (like Vltava in Prague); however, some events with high $R_{x}$ following after a dry period are characterised by rather low $Q_{x}$ because the flood wave could be transformed;
- in catchments representing extensive lowlands (e.g. Labe/Elbe), processes of flood wave transformation play a significant role. Thus, the sets of significant events in terms of $R_{x}$ and $Q_{x}$ partly differ;

- event rankings by $R_{x}$ and $Q_{x}$ can strongly differ in a complex catchment such as the Morava River. This can be explained by the crucial precipitation effect in the orographically exposed Bečva sub-catchment on the flow of the Morava in Strážnice. Thus, the ranking of precipitation events by $Q_{x}$ of the Morava in Strážnice is more similar to the ranking of precipitation events by $R_{x}$ in the Bečva river basin as compared to the entire catchment. Thus, when selecting by $Q_{x}$, significant events can be characterized by extreme precipitation amounts only in a crucial part of the catchment, not within the entire catchment.

The sets of the most significant events in terms of $Q_{x}$ and of $R_{x}$ are rather similar. However, they are not identical, mainly from the viewpoint of the ranking of the events within the set. Ranking events by $R_{x}$ yields much more similar results with ranking by $Q_{x}$ as compared to $Q_{\max }$ - thus supporting 


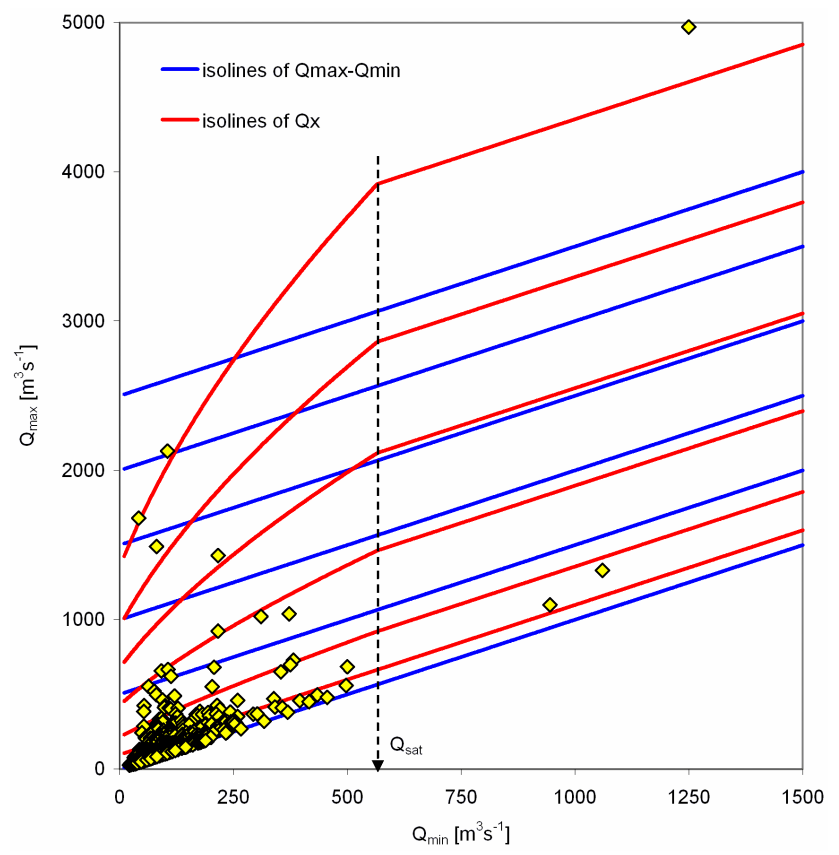

Fig. 2. Comparison between indicators $Q_{\max }-Q_{\min }$ and $Q_{x}$ on the Vltava River in Prague in summer half-years 1951-2002. The episodes with any discharge increase $\left(Q_{\max }>Q_{\min }\right)$ are represented by yellow signs. Naturally, the discharge increase is usually small so the signs are concentrated just above the line $Q_{\max }=Q_{\min }$. In this case, $Q_{\text {sat }}=577 \mathrm{~m}^{3} \mathrm{~s}^{-1}$. The selected isolines of $Q_{x}$ represent values from bottom 100, 500, 2000, 5000, 10000, and 20000 .

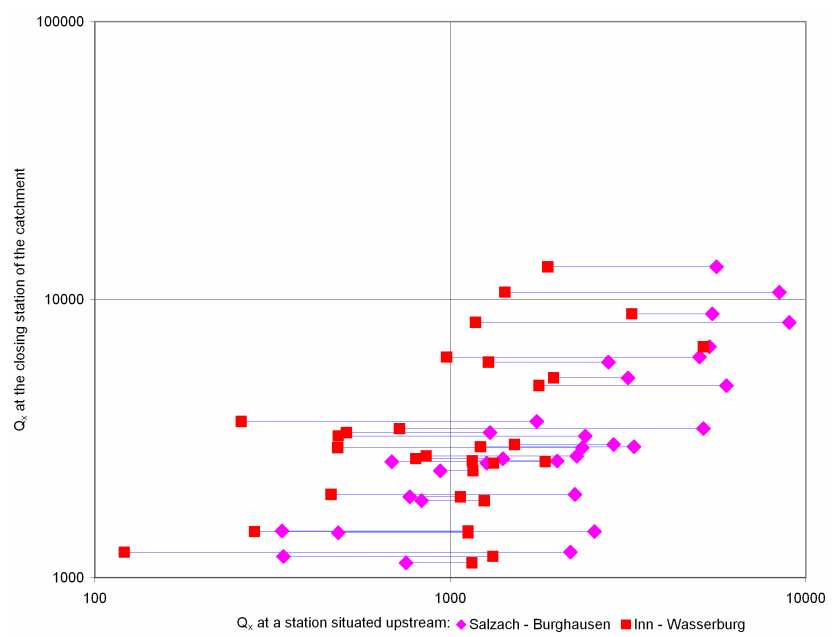

Fig. 3. Relation between $Q_{x}$ values at three stations in the Inn river basin: Burghausen, Wasserburg (x-axis), and Passau (y-axis). Only events with twenty highest $Q_{x}$ values at least at one of the stations are depicted.

the notion that a proper hydrological criterion of precipitation extremity should consider discharge increases and not only peak flows (compare Fig. 4a and b). With the suggested limitations in mind, the events with particularly high $Q_{x}$ val-
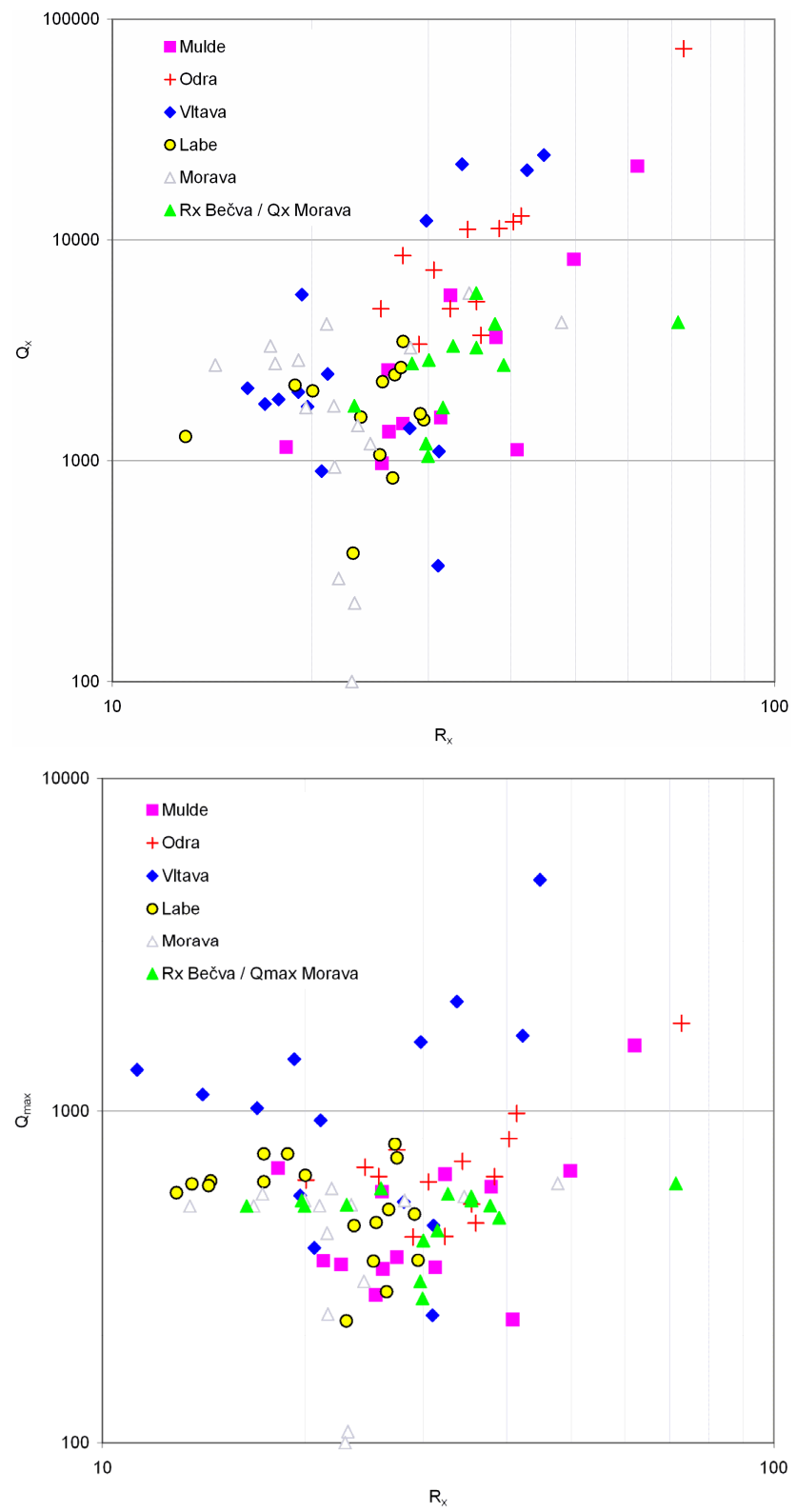

Fig. 4. Comparison of (a) $R x$ and $Q x$ values and (b) $R x$ and $Q_{\max }$ within five studied catchments. Ten highest values of each considered criterion within each catchment are depicted.

ues can be regarded as significant precipitation events during summer half-years within the river basin. However, as the ranking is only approximate, not all of them must necessarily belong to the most significant precipitation events. 


\section{Significant precipitation events in Central Europe from 1951 to 2002}

Significant precipitation events were selected by $Q_{x}$, following data accessibility. Figure 5 lists three events with the highest values of the criterion in every catchment. Only summer half-years were considered, even though winter precipitation events and floods are more significant in some catchments (see S/W values in Table 1). The given date refers approximately to the end of the precipitation event (date with $Q_{\max }$ ). If an event hit more than one river basin over several days, only the first day is mentioned.

\subsection{Spatial extent of events and their seasonal distribution}

Simultaneous occurrence of significant precipitation in more catchments can be studied from Fig. 5. Evidently, significant precipitation often hits two or more catchments simultaneously. If more than one catchment is hit, then these are usually neighbouring river basins. The ranking of lines and columns in Fig. 5 is motivated by the effort to put together the events, which affected the same catchments, and to put together the catchments, which are usually hit simultaneously. The main concentration of significant precipitation into several events was detected in the central part of the studied region. However, no event ever hit the entire region. Precipitation usually spread from the northern slopes of the Austrian Alps either into the western part of the region (Bohemia and Saxony) as in August 2002 or into the eastern one (Moravia, Silesia, and Western Slovakia) as in July 1997. This can be considered a consequence of cyclones moving from the Mediterranean into Central Europe along the so-called $\mathrm{Vb}$ track (van Bebber, 1883; Mudelsee et al., 2004). The most intense precipitation typically falls in a rather narrow band of enhanced horizontal pressure gradient in the leeward sector of the cyclone. The usually limited zonal range of the affected area is determined by the zonal component of the movement of the cyclone.

A synchronisation of significant precipitation appears at the south-eastern slopes of the Alps, too. Local precipitation events are quite isolated and rarely spread into other parts of Central Europe. Another area with a simultaneous occurrence of significant precipitation events is Western Germany. These events are characterised by a duration longer than three days. While these events often spread into the central part of the studied region, they are not so significant there.

The catchments were additionally investigated from the perspective of temporal distribution of significant precipitation events from May to October (Fig. 6). Even though only summer half-years were included, several regions with specific regimes of significant precipitation can be distinguished:

- Central region, comprising the Austrian Alps (Inn, Enns), the Czech Republic (Vltava, Labe, Odra, Morava), Saxony (Mulde, partly Saale), and Western
Slovakia (Váh). July and August is the dominant period in respect to significant precipitation events;

- South-eastern region - rivers running eastward from the Eastern Alps (Sava, Drava, partly Mura). Significant precipitation usually emerges in autumn;

- Eastern region, comprising Eastern-Carpathian Rivers (Somes, Mures, Olt). The first months of the warm halfyear (May to July) seem to be most important from the viewpoint of significant precipitation. However, it cannot be excluded that thawing could influence the values of $Q_{x}$ in May;

- Western region - rivers in the western part of Germany (Mosel, Neckar, Main). Summer half-year events are usually not very extreme unlike the typical dominance of winter heavy rains and floods. Detected events occurred mainly at the beginning of and at the end of the studied half-years.

\subsection{Exceptional events}

Considering the extent of the affected area, the size of the rivers, and the extremity of $Q_{x}$, several events can be highlighted in the study period as the most significant precipitation events in summer half-years:

- the August 2002 floods in Austria, Bohemia, and Saxony. Precipitation was extreme in the Vltava and Mulde catchments on 11-13 August. The hydrological effect was enhanced by a previous event five days earlier in southern Bohemia and in Austria (Ulbrich et al., 2003);

- the July 1997 floods in Moravia, Silesia, and Western Slovakia. Then, all criteria discussed above reached unprecedented values especially in the Odra river basin (Kundzewicz et al., 1999);

- the flood at the turn of October and November 1998 in the western part of Germany (Engel, 1998). The event occurred at the end of the summer half-year but its development was similar to the winter floods that are typical for this region;

- floods in the South-Eastern Carpathians in June and July 1975. The value of $Q_{x}$ was more than three times higher on 4 July 1975, then ever on Olt. Heavy rain affected the Eastern Alps, too; particularly the Enns river basin at the beginning of the event;

- significant precipitation hit rivers coursing from the Eastern Alps in September 1973. The event followed a dry period and the runoff values did not reach their maxima;

- extreme precipitation and floods affected eastern Europe in May 1970. Significant precipitation occurred in Western Europe only several days before; 


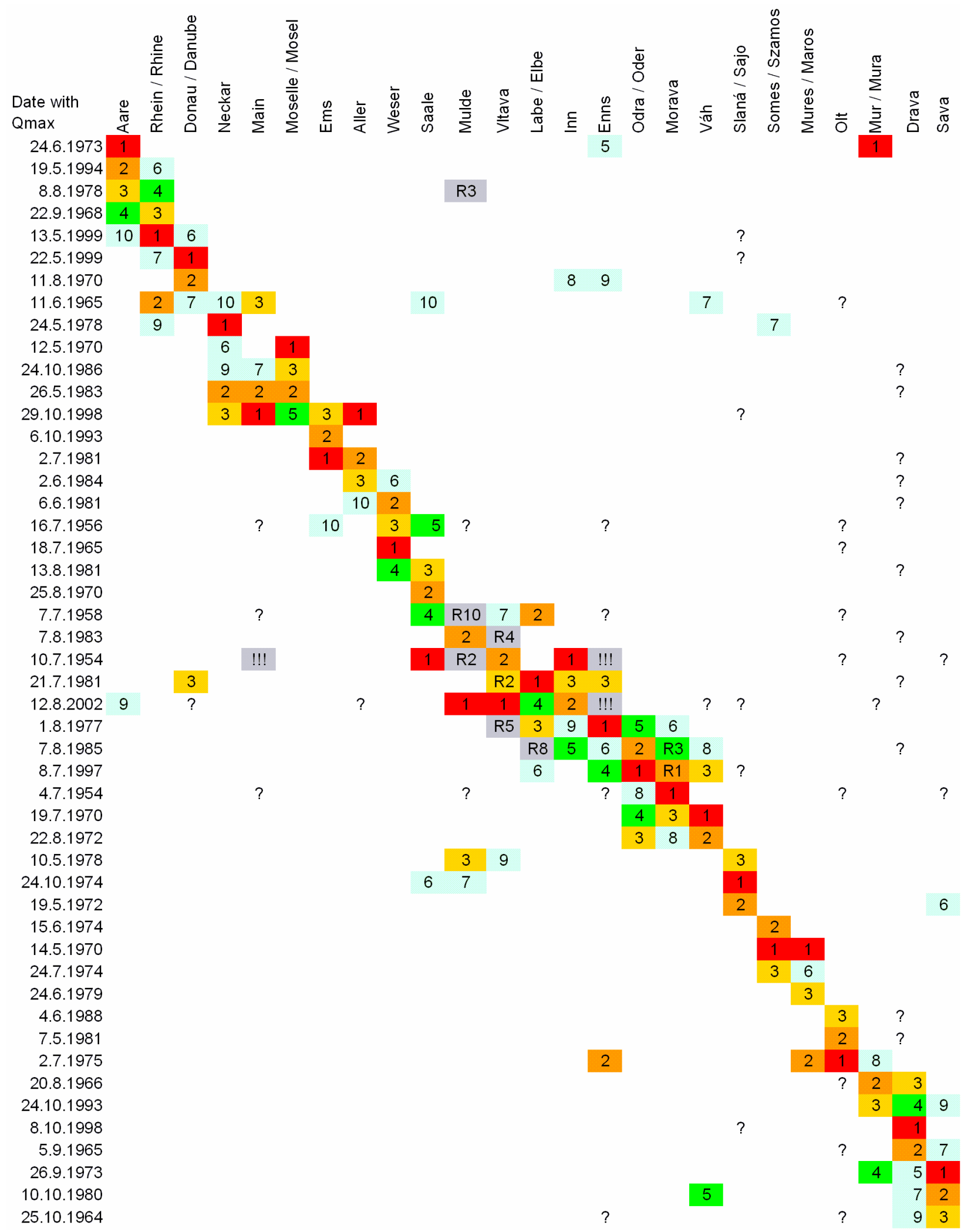

Fig. 5. Significant precipitation events in selected catchments. The three highest events in each catchment are listed (1-3) and highlighted by colours. If the event was detected as one of the 10 most significant events in another catchment, too, the related ranking is presented (4-10). Missing data are depicted with (?) or possibly (!!!) when significant precipitation certainly hit the catchment, too. If precipitation data were available, the possible ranking according to $R_{x}$ higher than according to $Q_{x}$ is given with prefix $R$. 


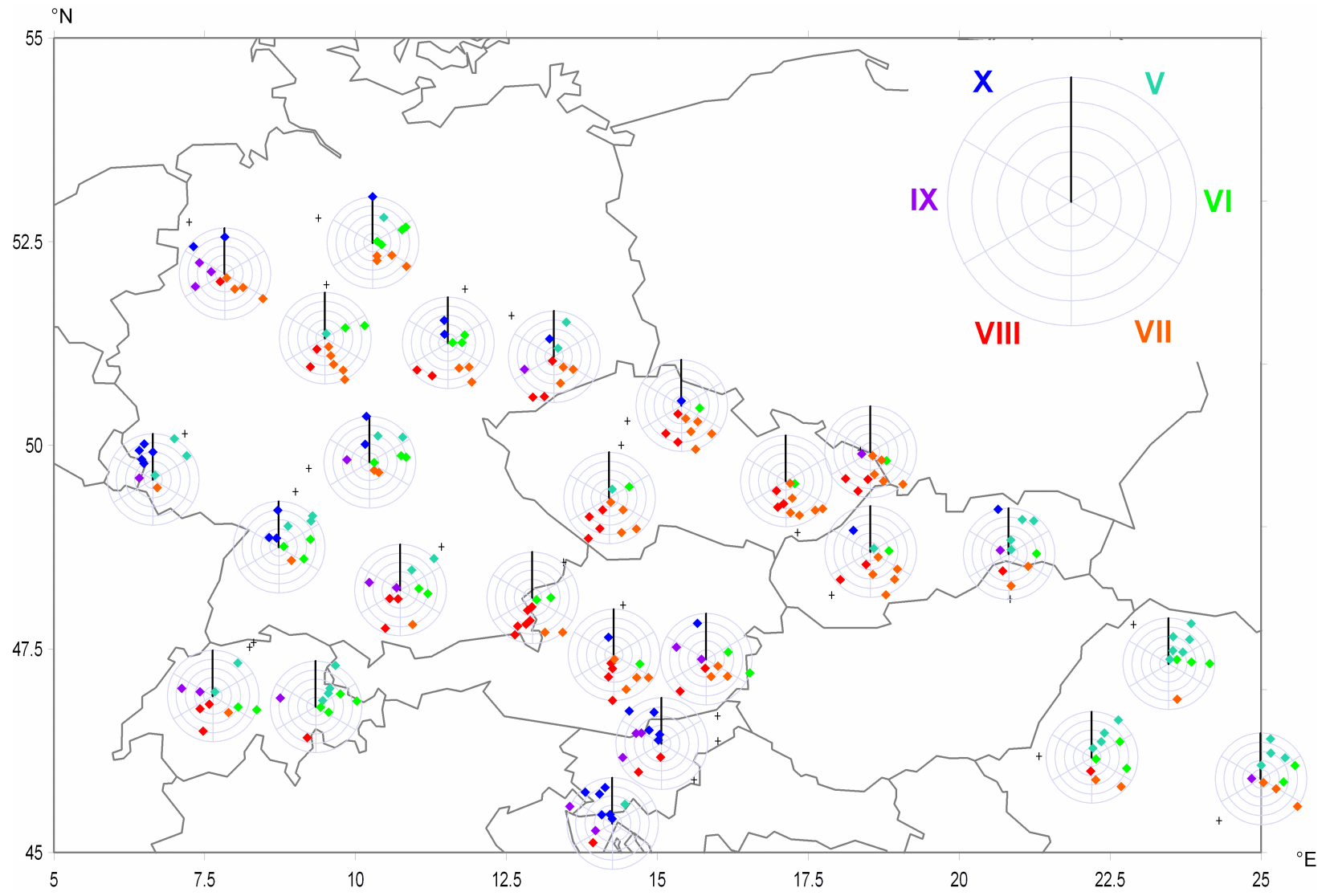

Fig. 6. Intra-annual variability of the occurrence of significant precipitation events in the catchments. Dots represent the ten events with highest $Q_{x}$ values in the catchment. The position of the dot relative to the centre of the diagram expresses when the event occurred (clockwise from May to October). The ranking of the event according to $Q_{x}$ is expressed by the distance from the centre of the diagram - the maximum is depicted at the external circle. The position of the discharge gauge stations, closing particular river basins, are indicated by small crosses $(+)$.

- the July 1954 floods in Austria, Bohemia, and Germany (H.Z.B., 1955). The extent was quite similar to August 2002 but precipitation spread unusually further the west (into the catchments of Saale, Main, and Aller).

\subsection{Temporal variability from 1951 to 2002}

The density of significant Central-European precipitation events during the studied period is depicted in Fig. 7. When the event symbols are located above the diagonal, it signals a period with less significant precipitation, and vice versa. Since the number of selected events is rather low, the stationarity was tested with respect to the binomial distribution with $95 \%$ tolerance interval. If there was a significant increasing or decreasing trend, the experimental curve would lie below the lower or above the upper blue curve, respectively. The events ranking has not to be considered absolutely accurate and the interannual variability is influenced by data leakage at the beginning of the studied period and the role of reservoirs in some catchments. However, some interpretations of this series can be presented:
- more significant precipitation events are concentrated in two periods: the 1970's with a maximum at the turn to the 1980's and in the second half of the 1990's;

- the most significant precipitation events (Sect. 3.2) are markedly accumulated in the first half of the 1970's and in the last few years of the study period;

- years around 1960 and mainly the second part of the 1980's and the early 1990's were characterised by less significant precipitation.

Despite any imperfection in the data series, the internal variability of the study period becomes clearly visible. No significant trend can be recognised in the frequency of significant precipitation events. Nevertheless, the proximity of periods with opposite character needs to be mentioned as an attribute of the last 15 years of the studied period. 


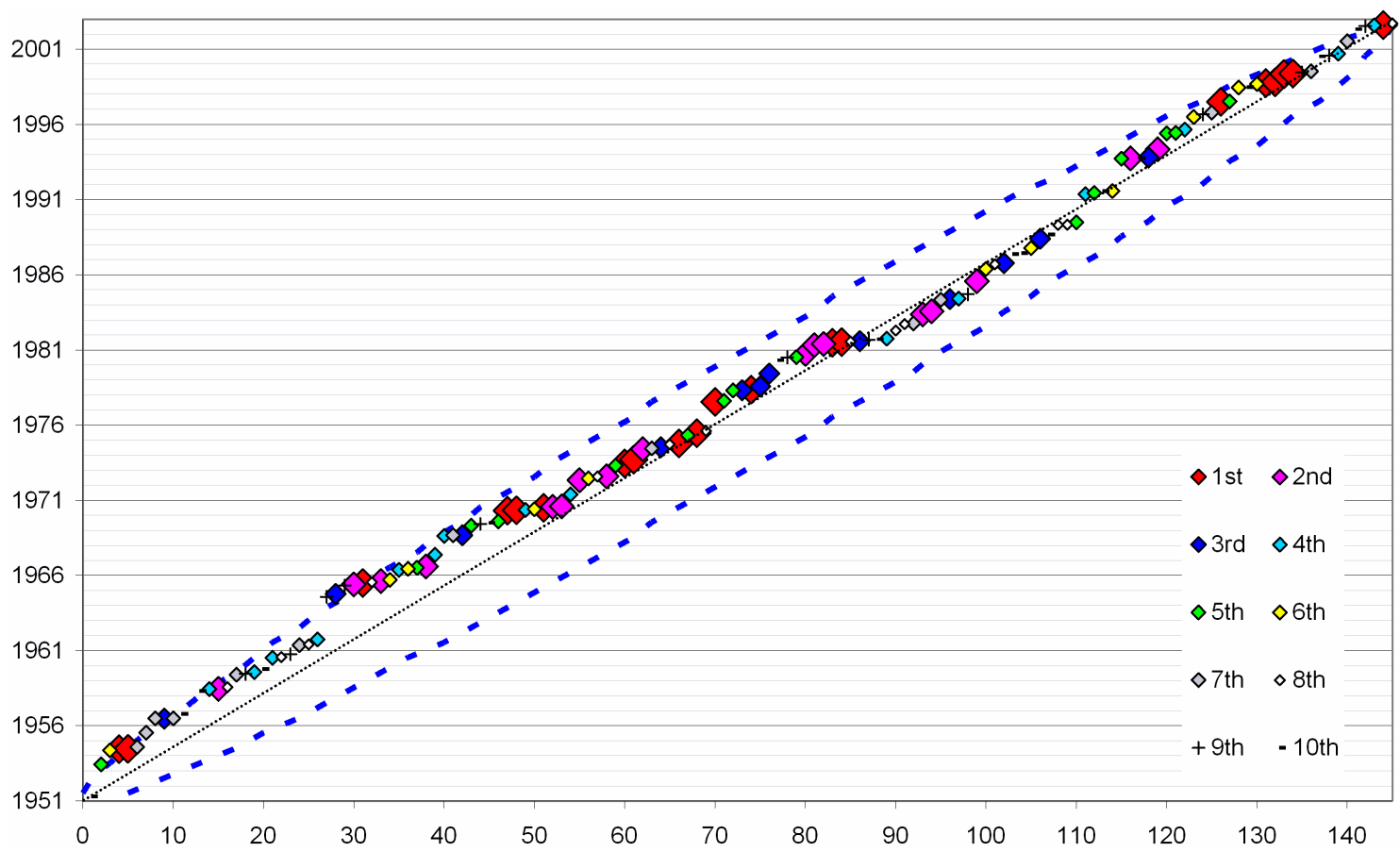

Fig. 7. Temporal distribution of 145 significant precipitation events in Ccentral Europe from 1951 to 2002. Ten events per catchment with the highest $Q_{x}$ values $(1 \mathrm{st}-10$ th) are depicted in the diagram. If an event hit more than one catchment, the sign represents the highest reached extremity. The blue dashed curves restrict the area with no significant trend in the frequency of events with $95 \%$ tolerance interval.

\section{Conclusions}

Selection of historically significant precipitation events that will be utilised in detecting their causes from the perspective of atmospheric circulation could be refined. It was demonstrated that runoff data can be used for this purpose in the summer half-years if a well-defined criterion is used. Such a criterion $Q_{x}$ is being suggested and tested using precipitation data. This criterion expresses the increase of a stream water volume and balances the impact of both the difference and the proportion of flow rates over several days in a row. Tests confirmed that the highest $Q_{x}$ values at a gauge station correspond with significant precipitation events, defined by weighted three-day areal precipitation totals in the catchment. The correspondence between precipitation and flow increase maxima is better in simple and in mountain catchments. In a more complicated basin with diverse characteristics of individual tributaries, the maxima of flow increase at the gauge station can represent significant precipitation events only in a crucial part of the catchment.

Ten significant precipitation events were selected in summer half-years from 1951 to 2002 in each of 25 catchments, and further studied in respect to spatial extent, simultaneous occurrence in different river basins, seasonal distribution, and temporal variability. There were 145 events instead of 250 since heavy precipitation often hits more than one river basin. Apart from neighbouring catchments, coincidence of significant precipitation events was confirmed between the Austrian Alps and i) Bohemia and Saxony, and ii) Moravia, Silesia, and Western Slovakia. The probable connection with the $\mathrm{Vb}$ track of Mediterranean cyclones will be studied further.

In respect to seasonality and simultaneous events occurrence, four regions could be distinguished within Central Europe. Significant events typically emerge in the central part of the region during peak summer, in the south-eastern area of the Alps during autumn months, in the South-Eastern Carpathians from May to July, and in western Germany in spring or autumn. Considering entire years, however, precipitation events are not so significant within the latter region.

Significant precipitation events were not distributed evenly over the studied time span. Considering all catchments together, two episodes with higher concentration of significant precipitation were recognised (1970 to 1981 and 1996 to 1999). In contrast, less significant precipitation characterised the years between these episodes, with a minimum at the beginning of the 1990's.

The prime target of our investigation was to select significant precipitation events in various parts of Central Europe since spatial variability of synoptic patterns that produce heavy precipitation is of major interest. A reasonable selection of reference events opens the door to a quantitative evaluation of dynamic and thermodynamic conditions typical for those events. Relations between large-scale anomalies 
of quantities representing such conditions and occurrence of significant precipitation in Central Europe are the object of further investigations.

Acknowledgements. This work was supported by the research program MSM 0021620831 and the projects GAAVCR KJB300420701 and KJB300420802. Special thanks go to the Deutsche Bundesstiftung Umwelt (DBU) for a scholarship to the first author which enabled his six months stay at TU Bergakademie Freiberg. The Global Runoff Data Centre (GRDC), 56068 Koblenz, Germany, is acknowledged for the runoff data, and the German Weather Service (DWD) for the data from Saxonian rain gauge stations.

Edited by: M.-C. Llasat

Reviewed by: M. Lang and another anonymous referee

\section{References}

Engel, H.: Hochwasser in Deutschland in den Monaten Oktober und November 1998, Bundesanstalf für Gewässerkunde, Koblenz, 12 pp., 1998 (in German).

H. Z. B. (Hydrographisches Zentral Büro im Bundesministerium für Land- und Forstwirtschaft, Umwelt und Wasserwirtschaft): Das Juli-Hochwasser 1954 im österreichischen Donaugebiet, Beitrag zur Hydrographie Österreichs, Wien, Heft Nr. 29, 139 pp., 1955 (in German).

Jansa, A., Genoves, A., Picornell, M. A., Campins, J., Riosalido, R., and Carretero, O.: Western Mediterranean cyclones and heavy rain. Part 2: Statistical approach, Meteorol. Appl., 8, 43-56, 2001.

Jung, T., Klinker, E., and Uppala, S.: Reanalysis and reforecast of three major European storms of the twentieth century using the ECMWF forecasting system. Part I.: Analyses and deterministic forecasts, Meteorol. Appl., 11, 343-361, 2004.

Kašpar, M. and Müller, M.: Selection of historic heavy large-scale rainfall events in the Czech Republic, Nat. Hazards Earth Syst. Sci., 8, 1359-1367, 2008, http://www.nat-hazards-earth-syst-sci.net/8/1359/2008/.

Kundzewicz, Z. W., Szamalek, K., and Kowalczak, P.: The great flood of 1997 in Poland, Hydrolog. Sci. J., 44(6), 855-870, 1999.

Martín, M. L., Santos-Muñoz, D., Morata, A., Luna, M. Y., and Valero, F.: An objectively selected case study of a heavy rain event in the Mediterranean Basin: A diagnosis using numerical simulation, Atmos. Res., 81, 187-205, 2006.

Mudelsee, M., Börngen, M., Tetzlaff, G., and Grünewald, U.: Extreme floods in central Europe over the past 500 years: Role of cyclone pathway "Zugstrasse Vb", J. Geophys. Res., 109, D23101, doi:10.1029/2004JD005034, 2004.

Porcú, F., Caracciolo, C., and Prodi, F.: Cloud systems leading to flood events in Europe: an overview and classification, Meteorol. Appl., 10, 217-227, 2003.

Řezáčová, D., Kašpar, M., Müller, M., Sokol, Z., Kakos, V., Hanslian, H., and Pešice, P.: A comparison of flood precipitation in August 2002 with historical extreme precipitation events from the Czech territory, Atmos. Res., 77, 354-366, 2005.
Ulbrich, U., Brücher, T., Fink, A. H., Leckebusch, G. C., Krüger, A., and Pinto, J. G.: The central European floods of August 2002: Part I. Rainfall periods and flood development, Weather, 58, 371377, 2003.

Ustrnul, Z. and Czekierda, D.: Circulation background of the atmospheric precipitation in Central Europe (based on the Polish example), Meteorol. Z., 10, 103-111, 2001.

van Bebber, J.: Typische Witterungserscheinungen, Zeitschrift der Österreichischen Gesellschaft für Meteorologie, 16, 447-458 (in German), 1883. 